\title{
PARTICLE SIZE ANALYSIS FOR IMPROVED SEDIMENTATION AND FILTRATION IN WASTE WATER TREATMENT
}

\author{
A. Tiehm, V. Herwig and U. Neis \\ Technical University of Hamburg-Harburg, Department of Waste Water \\ Management,Eißendorfer Str. 42, 21073 Hamburg, Germany
}

\begin{abstract}
Size distributions of particle mass, chemical oxygen demand (COD) and phosphorus at four municipal waste water treatment plants were investigated by fractionation of samples through 0.1-8.0 $\mu \mathrm{m}$ polycarbonate filters and 32-125 $\mu \mathrm{m}$ sieves, respectively. Particle size analysis of primary and secondary effluents at each plant showed significantly different size distribution functions. These distribution functions remained constant with respect to time under dry weather conditions so they can be considered as characteristical patterns for each sample location. Advanced treatment by deep bed filtration can be improved by taking into consideration the distribution pattern in the secondary effluents. In raw sewage and primary effluents $45-90 \%$ of COD and 35-80\% of phosphorus were associated with suspended solids. In the secondary effluents particulate COD drops to $14-45 \%$ but particulate phosphorus increases to 55$80 \%$. Conclusions are drawn for a better design of advanced contaminant reduction in connection with suspended solids removal processes.
\end{abstract}

\section{KEYWORDS}

COD; deep bed filtration; fractionation; particle size distribution; phosphorus; primary effluents; secondary effluents; suspended solids.

\section{INTRODUCTION}

Coastal waters throughout the world are threatened by man made liquid and solid wastes, for example the Black Sea, the Baltic Sea, the Mediterranean, the Caribbean Sea. In many instances urgent measures have to be taken to reduce actual pollution flows. Many different treatment methods are available and recommended to treat waste waters to adequate levels. From very simple low-cost technologies, to the highest level of sophistication, appropriate methods might be chosen. To determine the optimal treatment method for a particular waste water, its main pollution parameters must be known. Due to the strong association of suspended solids with waste water Chemical Oxygen Demand (COD) or phosphorus (P) (Levine et al., 1985), suspended solids (SS) have to be removed very efficiently to achieve the required effluent quality in highly sensitive coastal areas (Smith, 1984). SS effluent standards in these areas should normally be as low as 10 or $5 \mathrm{mg} / \mathrm{l}$.

Suspended solids play an important (and often underestimated) role in characterizing the treatability and hence the degree of contaminant removal of a waste water. The size of the suspended solids has considerable impact on separation processes such as sedimentation, flocculation and filtration (Alon and Adin, 1994; Kavanaugh et al., 1980; Stevenson, 1997). Furthermore, the biological degradation rate in terms of COD reduction is influenced by particle size distribution (Levine et al., 1991). 
Information regarding the association of waste water nutrients and contaminants with suspended solids of a particular size is rather limited (Levine et al., 1985; Yeoman et al., 1992). From the data available it cannot be concluded if smaller or larger particles are more important as carrier of water pollutants. Efficiency of nutrient and contaminant removal processes could be improved by knowing how these substances are associated with the particle size distribution of a particular waste water.

The objective of this study is to set up strategies for a more efficient SS/contaminant removal by carefully investigating the particle size distribution in primary and secondary sedimentation and in deep bed filtration.

\section{SAMPLING LOCATIONS AND METHODS}

Four municipal waste water treatment works located near Hamburg, Germany, were selected for this study. The treatment works differed widely in their operational concepts (table 1). Sampling was performed under dry weather conditions. At three of the plants sampling was performed during two distinctive time periods during 1995, 1996, and 1997.

Size fractionation of suspended solids was done with samples of raw sewage (plant A), primary effluents (plant B-D), and final effluents (plant A-D). A total of 89 composite grab samples was analysed in order to obtain statistically significant results. Fractionation of solids was performed by sieving through 125,50 , and $32 \mu \mathrm{m}$ pore sieves, or filtering through polycarbonate membrane filters with pore diameters between 0.1-8.0 $\mu \mathrm{m}$. Eight particle size fractions from each sample were obtained this way. Polycarbonate membrane filters were choosen because they show low unspecific adsorption and have a well defined porosity (Laxen and Chandler, 1982). It was confirmed repeatedly that no cake filtration occurred. Gravimetric determination of particle mass of the retained solids was done in triplicates for each pore size. COD and $\mathrm{P}$ were analyzed in all the samples fractionated in size classes from $0.1-8.0 \mu \mathrm{m}$.

Deep bed filtration of secondary effluents was performed in laboratory scale. Secondary effluent of a halftechnical waste water treatment plant was collected in a $1 \mathrm{~m}^{3}$ reservoir tank to obtain a constant influent in the filtration experiments. The deep bed filter column was $100 \mathrm{~cm}$ tall and $15 \mathrm{~cm}$ in diameter. Before performing the experiments, the deep bed filter was operated for 12 hours and back-washed. Filtration was done at a flow rate of $14 \mathrm{~m} / \mathrm{h}$. Samples were taken at different filter depths. Total suspended solids were determined by membrane filtration $(0.1 \mu \mathrm{m}$ polycarbonate filters). Particle size distribution was analyzed by laser light obscuration as described previously (Neis and Tiehm, 1997).

Table 1. Characterization of treatment works

Location Operational Units

A)

Ahrensburg

(P.E. 40,000)

B)

Stellingen

(P.E. 300,000)

C)

Seevetal

(P.E. 130,000)

D)

Bad Bramstedt

(P.E. 85,000) no primary clarifier,

two treatment lines:

1. anaerobic bio-P-elimination, pre-denitrification, activated sludge with nitrification;

2. high rate activated sludge (sludge age $<4$ days);

intermediate clarifier, trickling filter, flotation with $\mathrm{Al}_{2}\left(\mathrm{SO}_{4}\right)_{3}$ and $\mathrm{Fe}_{2}\left(\mathrm{SO}_{4}\right)_{3}$

primary clarifier,

activated sludge tank, $\mathrm{P}$ precipitation by simultaneous dosage of $\mathrm{FeSO}_{4}$,

secondary clarifier

primary clarifier,

pre-denitrification, activated sludge with nitrification,

$\mathrm{P}$ precipitation by simultaneous dosage of $\mathrm{NaAl}(\mathrm{OH})_{4}$, trickling filter, secondary clarifier

primary clarifier,

anaerobic bio-P-elimination, pre-denitrification, activated sludge with nitrification,

$\mathrm{P}$ precipitation by simultaneous dosage of $\mathrm{FeClSO}_{4}$,

secondary clarifier 


\section{RESULTS AND DISCUSSION}

\section{Size distribution of particle mass}

The analysis of the particle size distributions of primary effluents at Stellingen, Seevetal, and Bad Bramstedt resulted in typical size distribution functions that differed only little (Fig. 1). At each plant the primary settling tanks are rectangular and are designed according to the German design criteria. The design hydraulic overflow is $\mathrm{v}_{\mathrm{s}}=1.0 \mathrm{~m} / \mathrm{h}$. This design concept is based on the theoretical correlation between the overflow rate and the settling velocity of particles. In reality, the flow conditions as well as the characteristics of the particles to be separated, always deviate from the theoretical assumptions. However it is interesting to compare the actual particle removal performances of the settling tanks with the design assumptions. Theoretically in the effluent of a settling tank designed to $\mathrm{v}_{\mathrm{s}}=1.0 \mathrm{~m} / \mathrm{h}$ no (spherical) particle with a diameter larger than $50 \mu \mathrm{m}$ should be present. The particle size distribution functions in fig. 1 show that the Stellingen primary settling tank operates quite well in agreement to theory because only $2 \%$ of the SS in the outgoing flow are larger than $50 \mu \mathrm{m}$. In Seevetal and Bad Bramstedt the compliance with theory is less, there are still about $10 \%$ of the SS larger than $50 \mu \mathrm{m}$. In Ahrensburg the flow to the biological units logically is characterized much more by large particles since the plant is operated without primary settling.

Particle size distribution functions obtained throughout the sampling periods in 1995, 1996, and 1997 remain more or less unchanged as is demonstrated in fig. 2. The hydraulic conditions influencing the settling process in the tanks are obviously rather stable under dry weather conditions. The particle size distribution function hence constitutes a characteristic feature of the particular settling tank.

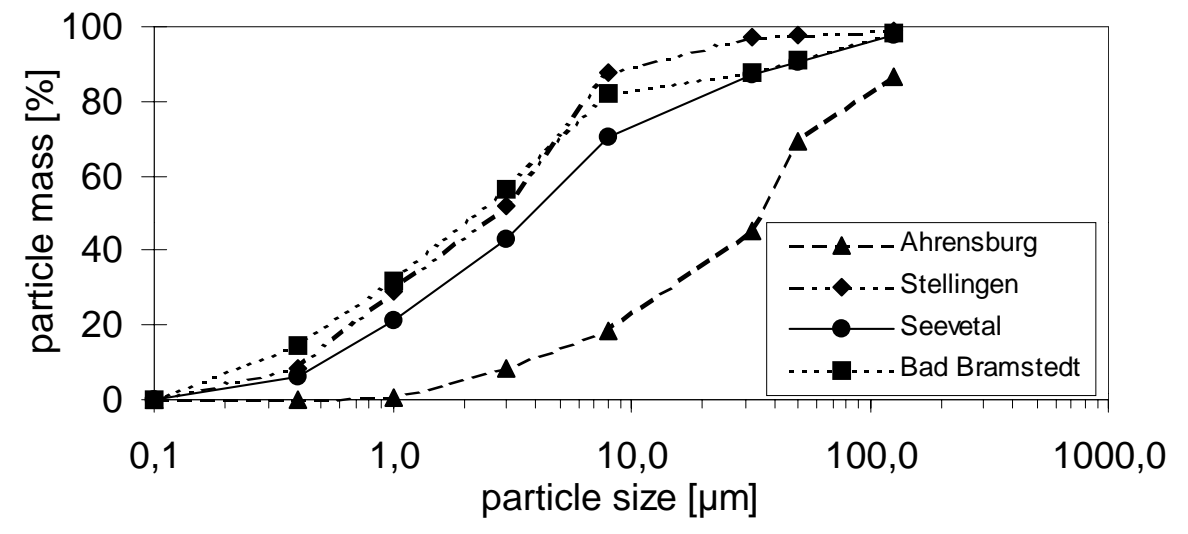

Figure 1.

Particle size distributions in the raw sewage at Ahrensburg and the primary effluents at Stellingen, Seevetal and Bad Bramstedt (average values of at least 5 samples).
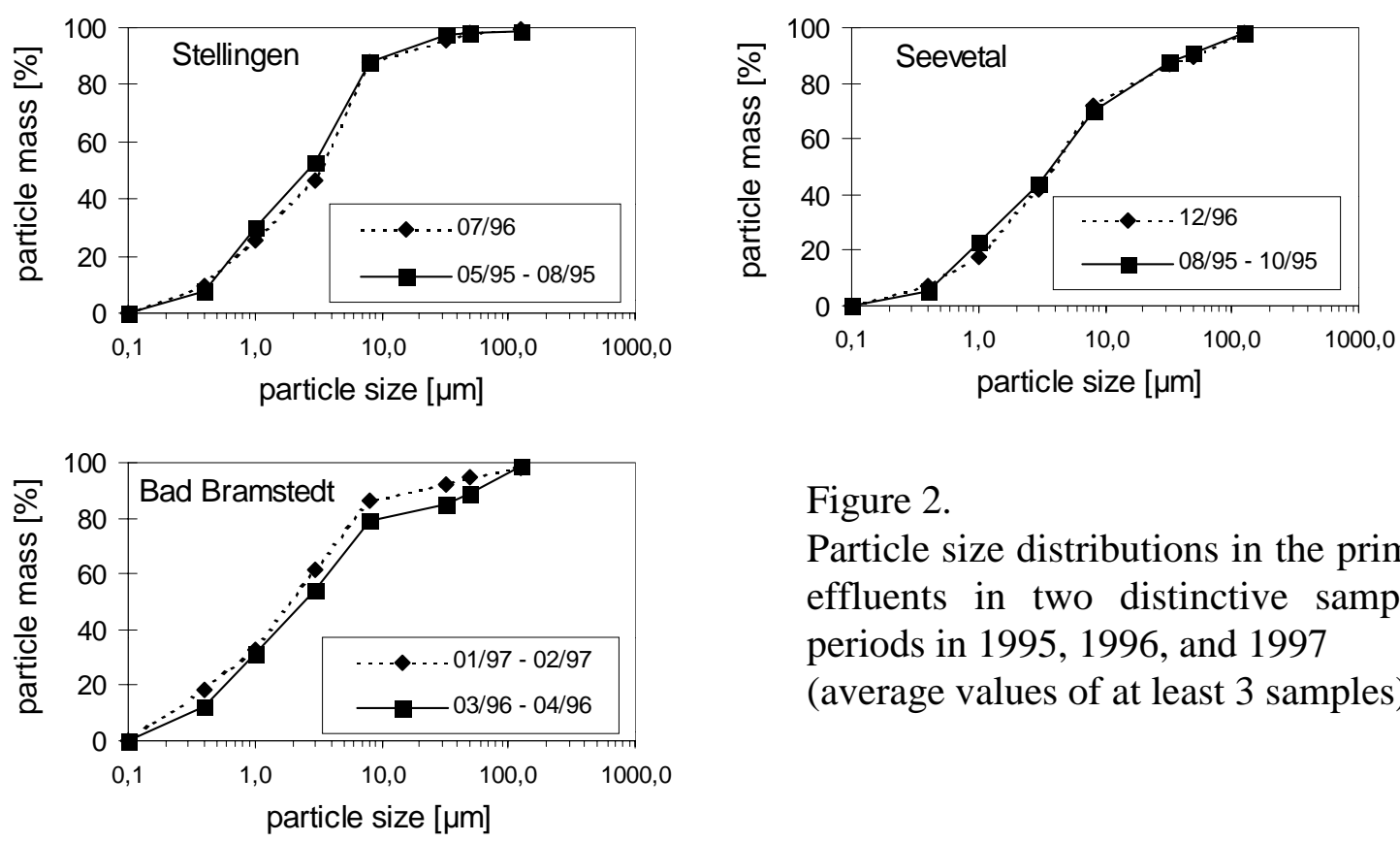

Figure 2.

Particle size distributions in the primary effluents in two distinctive sampling periods in 1995, 1996, and 1997 (average values of at least 3 samples). 
Secondary clarifiers in Germany are designed to play a multifunctional role. Besides the settling function there is the holding tank function to prevent the loss of biomass. So their design is partly different from that of primary sedimentation basins.

Fig. 3 clearly shows very different size distribution functions compared to fig.1. There were many more larger particles in the final effluents as compared to primary effluents. Although the clarifiers were operated at similar hydraulic overflow rates $\mathrm{v}_{\mathrm{s}}$ of about $0.4 \mathrm{~m} / \mathrm{h}$, there were considerable differences in the shape of the particle size distribution functions (fig.3, fig.4). For example, only $9 \%$ of suspended solids in the effluent at the Stellingen plant was larger than $32 \mu \mathrm{m}$ as compared to $55 \%$ in Seevetal. However the average effluent SS concentration in Seevetal was only $12.2 \mathrm{mg} / \mathrm{L}$ as compared to $19.2 \mathrm{mg} / \mathrm{L}$ in Stellingen (table 2). This indicates that the sedimentation process in the secondary clarifier in Seevetal could be even further improved notwithstanding the already low average SS concentration. The secondary clarifier in Stellingen works well, the SS concentration is $19.2 \mathrm{mg} / \mathrm{L}$. If a more stringent effluent standard would be imposed here only filtration or flotation would be the choice, sedimentation in Stellingen is more or less at its effective limits.

One interesting objective in using particle size analysis (PSA) would be the assessment of the functionality of secondary clarifiers under increasing hydraulic loads in wet weather conditions. In many places secondary clarifiers perform very poorly under these circumstances and PSA would be of great help to determine the maximum acceptable hydraulic load of a particular tank.

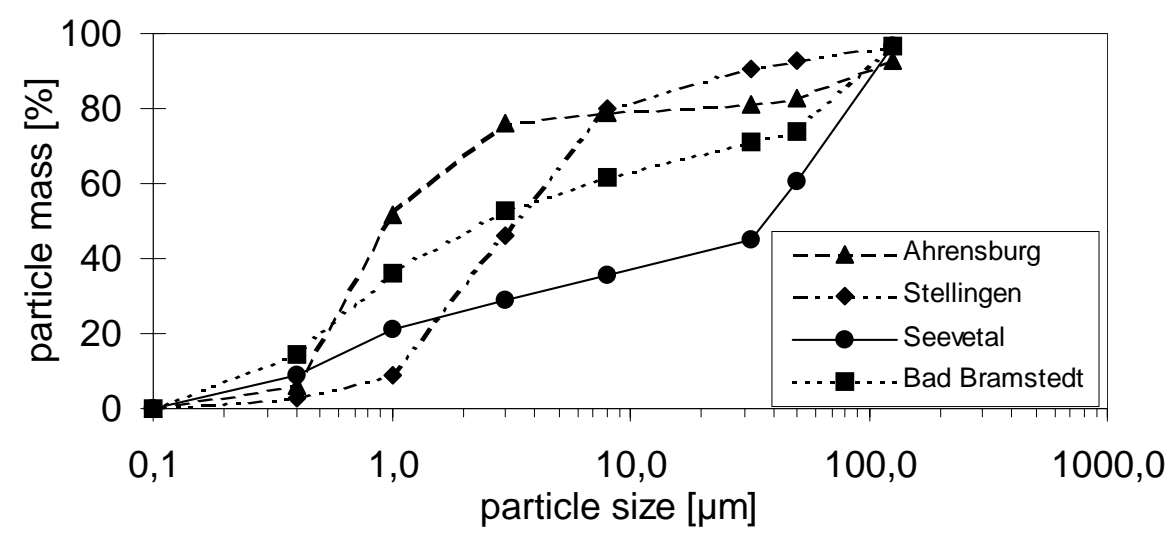

Figure 3.

Particle size distributions in the final effluents (average values of at least 6 samples at each treatment plant).
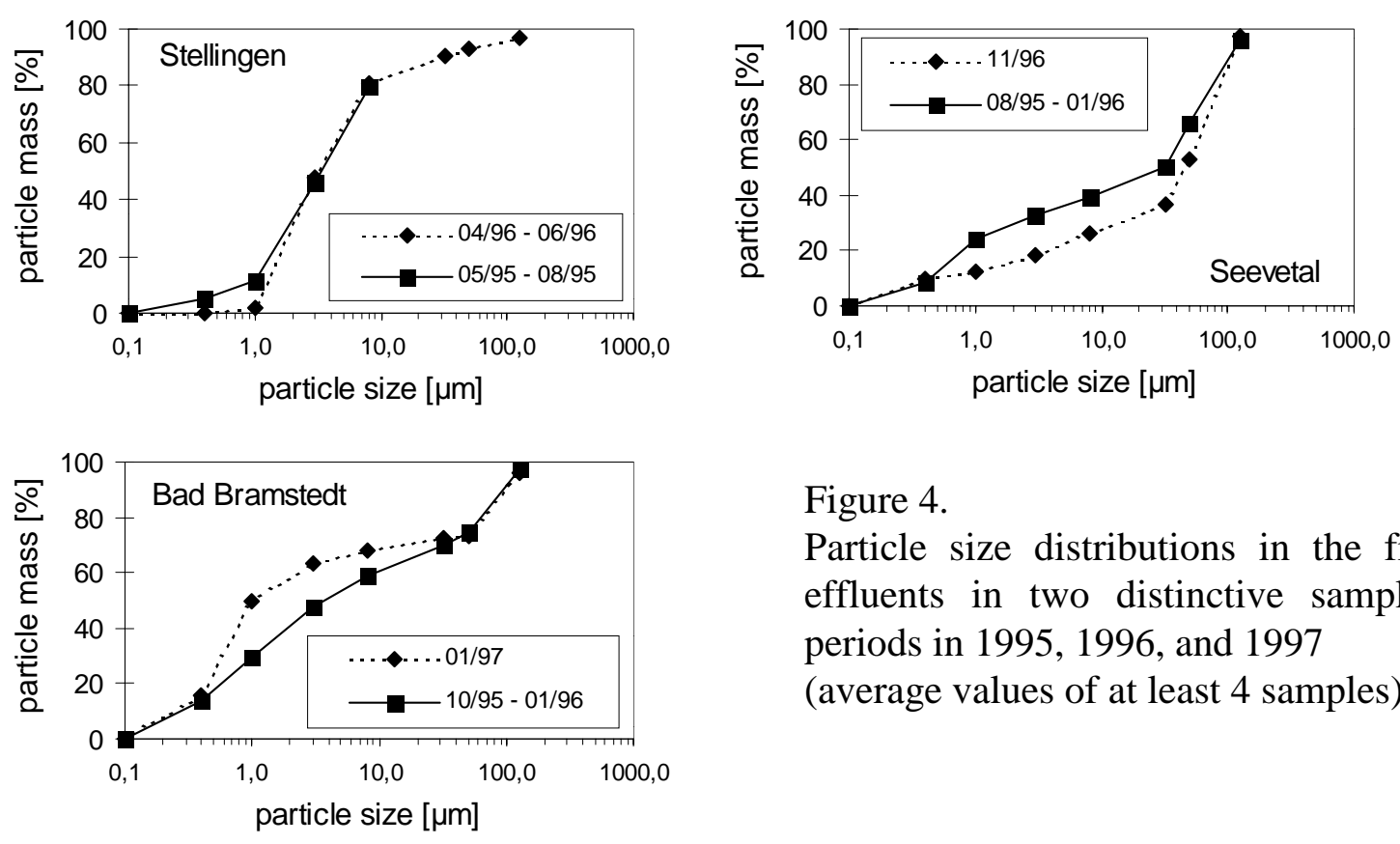

Figure 4.

Particle size distributions in the final effluents in two distinctive sampling periods in 1995, 1996, and 1997 (average values of at least 4 samples). 
Fractionated filtration of waste water samples revealed that considerable amounts of COD and phosphorus were particulate (table 2). $91 \%$ of the raw sewage COD, 46-71\% of the primary effluents COD, and $14-46 \%$ of the final effluents COD were attributed to suspended solids. In case of phosphorus, the particle associated fraction was $79 \%$ in raw sewage, $35-67 \%$ in the primary effluents, and $54-81 \%$ in the final effluents.

Average ratios of particulate $\mathrm{COD} /$ particle mass decreased from 1.6-1.7 $\mathrm{mg} \mathrm{COD} / \mathrm{mg} \mathrm{SS}$ in the primary effluents to $0.7-0.9 \mathrm{mg} \mathrm{COD} / \mathrm{mg} \mathrm{SS}$ in the final effluents due to biodegradation processes.

Particulate P/particle mass ratios were between 19-28 $\mu \mathrm{g} \mathrm{P} / \mathrm{mg}$ SS in raw sewage and primary effluents. The ratios of particulate P/particle mass varied from $20 \mu \mathrm{g} \mathrm{P} / \mathrm{mg} \mathrm{SS}$ to $48 \mu \mathrm{g} / \mathrm{mg}$ SS in the final effluents. It seems reasonable to assume that the different types and efficiencies of chemical precipitation used to eliminate phosphorus (table 1) are mainly determining the phosphorus fraction of the suspended solids.

Table 2. Suspended solids, total and particulate COD and phosphorus in raw sewage, the primary and the final effluents (average values of at least 5 samples)

\begin{tabular}{|c|c|c|c|c|c|c|c|}
\hline \multirow[t]{2}{*}{ Sample Source } & \multirow{2}{*}{$\begin{array}{c}\text { Suspended } \\
\text { Solids } \\
>0.1 \mu \mathrm{m} \\
{[\mathrm{mg} / \mathrm{l}]}\end{array}$} & \multicolumn{3}{|c|}{ COD } & \multicolumn{3}{|c|}{ Phosphorus } \\
\hline & & $\begin{array}{c}\text { total } \\
{[\mathrm{mg} / \mathrm{l}]}\end{array}$ & $\frac{>0.1 \mu \mathrm{m}}{[\%]}$ & $\frac{\mathrm{COD} / \mathrm{SS}}{[\mathrm{mg} / \mathrm{mg}]}$ & $\frac{\text { total }}{[\mathrm{mg} / \mathrm{l}]}$ & $\frac{>0.1 \mu \mathrm{m}}{[\%]}$ & $\frac{\mathrm{P} / \mathrm{SS}}{[\mu \mathrm{g} / \mathrm{mg}]}$ \\
\hline \multicolumn{8}{|l|}{ raw sewage: } \\
\hline Ahrensburg & 1544 & 1908 & 91 & 1.1 & 36.8 & 79 & 19 \\
\hline \multicolumn{8}{|l|}{ primary effluent: } \\
\hline Stellingen & 143 & 439 & 54 & 1.7 & 9.2 & 35 & 23 \\
\hline Seevetal & 176 & 411 & 71 & 1.7 & 8.1 & 44 & 20 \\
\hline Bad Bramstedt & 211 & 752 & 46 & 1.6 & 8.8 & 67 & 28 \\
\hline \multicolumn{8}{|l|}{ final effluent: } \\
\hline Ahrensburg & 6.0 & 31 & 14 & 0.7 & 0.3 & 68 & 34 \\
\hline Stellingen & 19.2 & 67 & 23 & 0.8 & 1.7 & 54 & 48 \\
\hline Seevetal & 12.2 & 41 & 28 & 0.9 & 0.8 & 58 & 38 \\
\hline Bad Bramstedt & 39.7 & 82 & 46 & 0.9 & 1.0 & 81 & 20 \\
\hline
\end{tabular}

Ratios of particulate $\mathrm{P}$ to particle mass related to particular size classes are shown for the final effluents (fig. 5). In the Seevetal effluent the suspended solids $>8.0 \mu \mathrm{m}$ showed the highest concentration of P/SS whereas in the Stellingen effluent P/SS was highest in the size fraction from 3.0 to $1.0 \mu \mathrm{m}$. Neither in the final effluents nor in raw sewage or primary effluents a significant increase of the ratio of P/SS or $\mathrm{COD} / \mathrm{SS}$ in the small size fractions was observed.

It has also been reported for heavy metals (Yeoman et al., 1989; Yeoman et al., 1992) and organic dyes (Andreadakis, 1993) that ratios of contaminants to particle mass were not increased in the small size fractions. If the association process would mainly be a solid surface adsorption type process a stronger association to smaller particles would be observed because of their larger specific surface. The more or less random distribution of contaminants in different particle size classes points to a porous structure of suspended particles. Therefore, from a practical point of view, it is important to remove particle mass efficiently throughout the whole particle size range. 


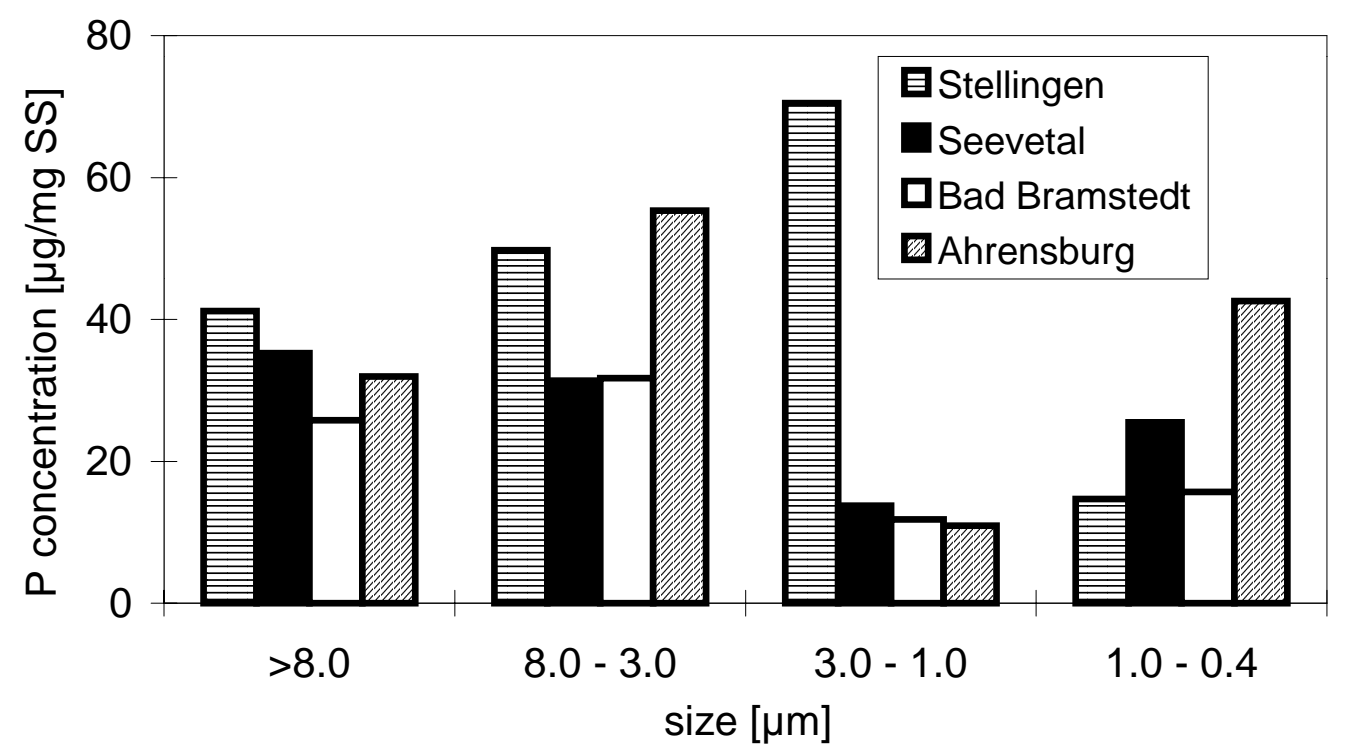

Figure 5. Ratio of particulate phosphorus to suspended solids in the final effluents in particular size classes (average values of 6 samples are indicated).

\section{Particle size analysis in deep bed filtration}

Up until now, particle size distributions are not considered for the design of deep bed filters in tertiary waste water treatment. Therefore the effect of filter grain size on removal of suspended solids in secondary effluent was investigated. The filtration efficiency was studied for quartz sand with two grain sizes of $2.0-3.0 \mathrm{~mm}$ and $0.8-1.2 \mathrm{~mm}$. Grab samples were taken at different filter depths. Total suspended solids and particle size distributions were analyzed.

There was a significant effect of filter grain size on particle removal. Figure 6 represents instantaneous values after 2 hours of filtration. The elimination of total particle mass was $30 \%$ for the large grain sizes and $74 \%$ for the small grain sizes, respectively. In case of the larger grains, large particles were detected in the filter effluent. In case of the smaller grains, most of the suspended solids were removed after filtration through a $10 \mathrm{~cm}$ layer at the filter top. The larger particles were completely retained. In both cases, the smallest fraction of suspended solids was increased in the filter columns as compared with the filter influent. This effect was more pronounced in the filter column containing the smaller grains. Probably, larger aggregates of suspended solids were reduced to smaller particles by shear forces.

This study demonstrates that particle size analysis is a valuable tool to investigate deep bed filtration. Our future studies will focus on selection of most efficient filter materials and flow rates to remove particles of a particular size class. It is expected that tertiary treatment can be significantly improved by taking into consideration the particle size distribution of secondary effluents. 


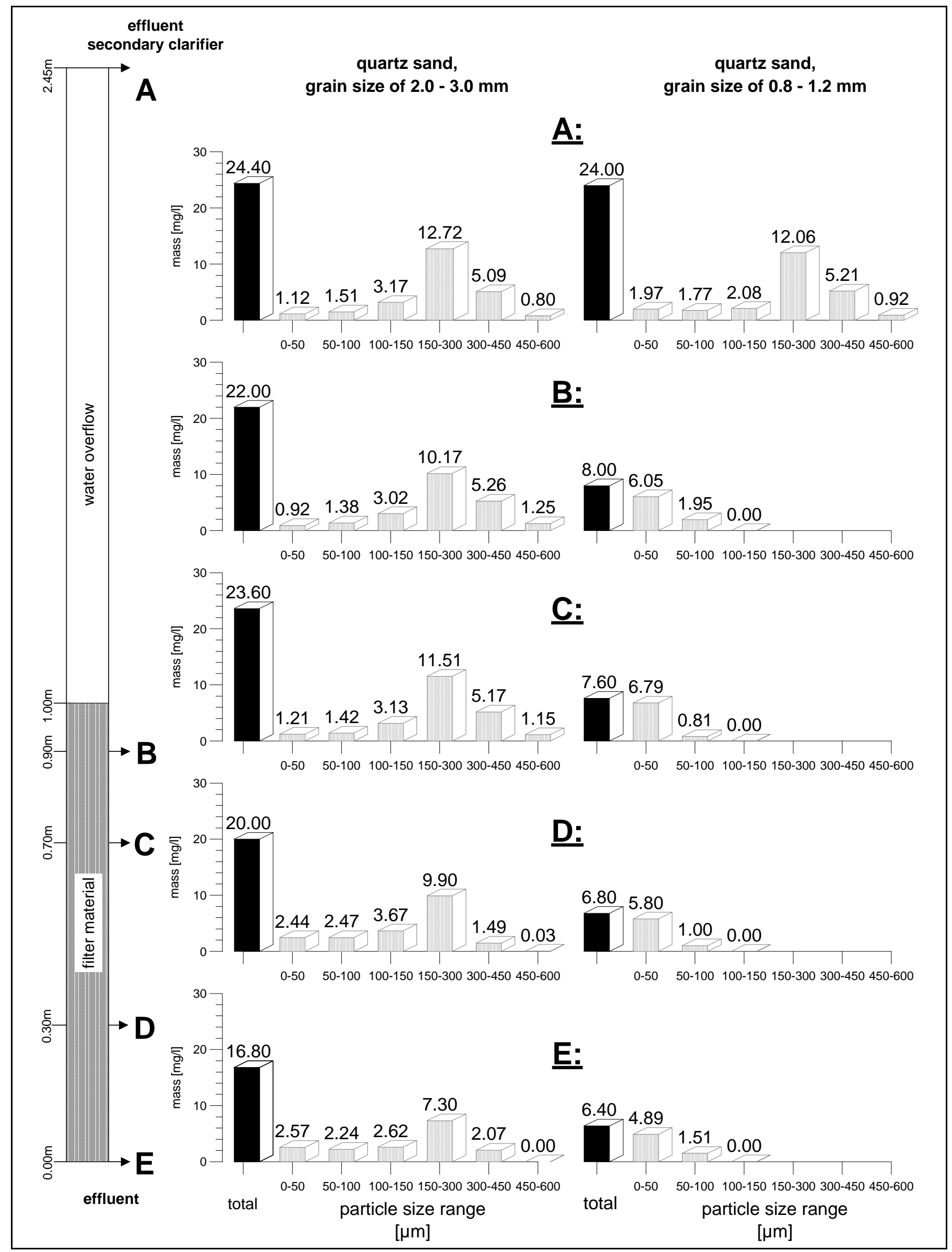

Figure 6. Effect of filter grain size (left column: 2.0 - 3.0mm; right column: $0.8-1.2 \mathrm{~mm}$ ) on removal of suspended solids in deep bed filtration. Total suspended solids and particle size distributions are shown in (A) the secondary effluent, (B) in a filter depth of $10 \mathrm{~cm},(\mathrm{C})$ in a filter depth of $30 \mathrm{~cm}$, (D) in a filter depth of $70 \mathrm{~cm}$, and (E) in the filter effluent corresponding to a filter depth of $100 \mathrm{~cm}$. 


\section{CONCLUSIONS}

This study demonstrates that a remarkable part of the waste water COD and phosphorus is related to the suspended solids. Therefore, efficient removal of suspended solids is necessary to protect highly sensitive coastal areas. Fractionated filtration revealed that neither in the final effluents nor in raw sewage or primary effluents was a significant increased ratio of P/SS or COD/SS in the small size fractions. Due to the more or less random distribution of particulate contaminants, it is important to obtain efficient overall particle mass removal. Specific particle size distributions obtained at the different treatment plants would encourage taking size distributions into consideration when evaluating and optimizing the performance of sedimentation tanks or designing advanced treatment units, e.g. deep bed filtration.

\section{ACKNOWLEDGEMENT}

The authors wish to thank the German Federal Ministry for Education and Research (BMBF) for the financial support of this project (grant no. 02WA9439). A financial contribution by the Oswald-SchulzeFoundation (grant no. AZ 724/94) towards the establishment of the particle analysis equipment is acknowledged with gratitude. Financial support for the dissemination of results and research coordination is given by the European Union within the framework of the EU programme „Avicenne“ (grant no. 93 AVI 076).

\section{REFERENCES}

Alon G. and Adin A. (1994) Mathematical modeling of particle size distribution in secondary effluent filtration. Water Environ. Res. 66, 836-841

Andreadakis A.D. (1993) Physical and chemical properties of activated sludge. Wat. Res. 27, 1707-1714

Kavanaugh M.C., Tate C.H., Trussell A.R., Trussell R.R., and Treweek G. (1980) Use of particle size distribution measurements for selection and control of solid/liquid separation processes. In: Kavanaugh M.C. and Leckie J.O. (ed.) Particulates in water, Advances in chemistry series 189, ACS, 305-328

Laxen D.P.H. and Chandler I.M. (1982) Comparison of filtration techniques for size distribution in freshwater. Anal. Chem. 54, 1350-1355

Levine A.D., Tchobanoglous G. and Asano T. (1985) Characterization of the size distribution of contaminants in wastewater: treatment and reuse implications. J. Wat. Pollut. Control Fed. 57, $805-816$

Levine A.D., Tchobanoglous G., and Asano T. (1991) Size distribution of particulate contaminants in wastewater and their impact on treatability. Wat. Res. 25, 911-922

Neis U. and Tiehm A. (1997) Particle size analysis in primary and secondary effluents. Wat. Sci. Tech. 36(4): 151-158

Smith S.V (1984) Phosphorus versus nitrogen limitation in the marine environment. Limnol. Oceanogra. 29(6): 1149-1161

Stevenson D.G. (1997) Flow and filtration through granular media - The effect of grain and particle size dispersion. Wat. Res. 31(2): 310-322

Yeoman S., Lester J.N. and Perry R. (1992) Phosphorus removal and its influence on particle size and heavy metal distribution during wastewater treatment. Environ. Technol. 13, 901-924

Yeoman S., Sterritt R.M., Rudd T., and Lester J.N. (1989) Particle size fractionation and metal distribution in sewage sludges. Water, Air and Soil Pollution 45, 27-42 